\title{
Use of intravascular ultrasound for in vivo assessment of changes in intimal thickness of angiographically normal saphenous vein grafts one year after aortocoronary bypass surgery
}

\author{
T Hozumi, J Yoshikawa, K Yoshida, T Akasaka, T Takagi, Y Honda, H Okura
}

\begin{abstract}
Objective-To use intravascular ultrasound in vivo to evaluate changes in the intimal thickness of angiographically normal saphenous vein grafts one year after implantation.

Design-Fifteen saphenous vein grafts in 12 patients were examined one month and 12 months after aortocoronary bypass graft surgery with intravascular ultrasound using a $30 \mathrm{MHz}$ transducer. None of the grafts examined showed any angiographic abnormalities. The intimal thickness and intimal area of the graft in the proximal portion were measured on intravascular ultrasound images obtained one month and 12 months after operation. Setting-General hospital.

Patients-Twelve patients who underwent aortocoronary bypass graft surgery

Results-The ultrasound images showed a thin-walled graft with a thin intima one month after operation (mean (SD)) $(0 \cdot 31$ $(0.09) \mathrm{mm})$. The intimal thickness of the graft increased significantly to $0.65(0.08)$ mm $(P<0.001) 12$ months after operation. The intimal area of the graft was $0.90(0.80) \mathrm{mm}^{2}$ one month after operation. 12 months after operation the intimal area had increased significantly to $5.26(1.38) \mathrm{mm}^{2}(P<0.001)$.

Conclusion-Intravascular ultrasound in vivo showed that one year after implantation angiographically normal saphenous vein grafts had a thicker intima than one month after implantation.
\end{abstract}

(Heart 1996;76:317-320)

Division of Cardiology, Kobe General Hospital, Kobe, Japan

T Hozumi

K Yoshida

T Akasaka

T Takagi

Y Honda

H Okura

First Department of Internal Medicine, Osaka City University School of Medicine, Osaka, Japan

J Yoshikawa

Correspondence to:

Dr T Hozumi, Division of Cardiology, Kobe General Hospital, 4-6 Minatojimanakamachi, Chuo-ku, Kobe 650, Japan.

Accepted for publication 8 May 1996

Use of saphenous vein grafts as aortocoronary bypasses is widespread for the treatment of coronary artery disease. There are several reports of intimal thickening in saphenous vein grafts after implantation. ${ }^{1-7}$ To our knowledge, however, there have been no in vivo studies of serial changes in intimal thickness in saphenous vein grafts after implantation except by contrast angiographic examination. ${ }^{6}$ Though this technique is capable of revealing wall irregularities and localised or diffuse severe narrowing, pathology-angiography correlation studies demonstrated marked angiographic underestimation of atheromatous plaque..$^{8-10}$ Thus angiography has limitations when it is used to evaluate the morphological characteristics of the vessel wall.

Intravascular ultrasound can accurately measure the luminal dimensions of vessels and image their morphological characteristics. ${ }^{11-20}$ We have used a new method to evaluate in vivo the changes in intimal thickness in angiographically normal saphenous vein grafts one year after implantation.

\section{Patients and methods}

PATIENTS

We examined 18 consecutive patients undergoing aortocoronary bypass surgery with saphenous vein grafts. Five patients were excluded because the ultrasound image quality was inadequate for precise measurements. One patient was excluded because the graft examined was occluded 12 months after operation. Therefore, our study population consisted of 12 patients: eight men and four women (mean (SD) age 60 (7)). All patients underwent coronary angiography one month and 12 months after operation. The examination was designed for this study protocol. Twenty two grafts were examined with intravascular ultrasound in these patients. Seven grafts, however, were excluded because it was difficult to obtain adequate ultrasound images. Thus 15 grafts were finally analysed. Three saphenous vein grafts were sutured to the left anterior descending coronary artery, nine grafts to the right coronary artery, and three grafts to the circumflex coronary artery. None of these grafts showed abnormalities in angiograms obtained one month and 12 months after operation. All participants gave informed consent to the protocol, which was approved by the Committee for the Protection of Human Subjects in Research at Kobe General Hospital.

\section{INTRAVASCULAR ULTRASOUND IMAGING} PROCEDURE

Fifteen vein grafts in twelve patients were examined with intravascular ultrasound at the time of the follow up angiography. Intravascular imaging was obtained with a $30 \mathrm{MHz}$ ultrasound transducer enclosed within an acoustic housing on the tip of a $4.3 \mathrm{~F}$, flexible catheter (CVIS). This catheter-based system provides real-time images of vessel cross sections with an axial resolution of about $70 \mu \mathrm{m}$ 


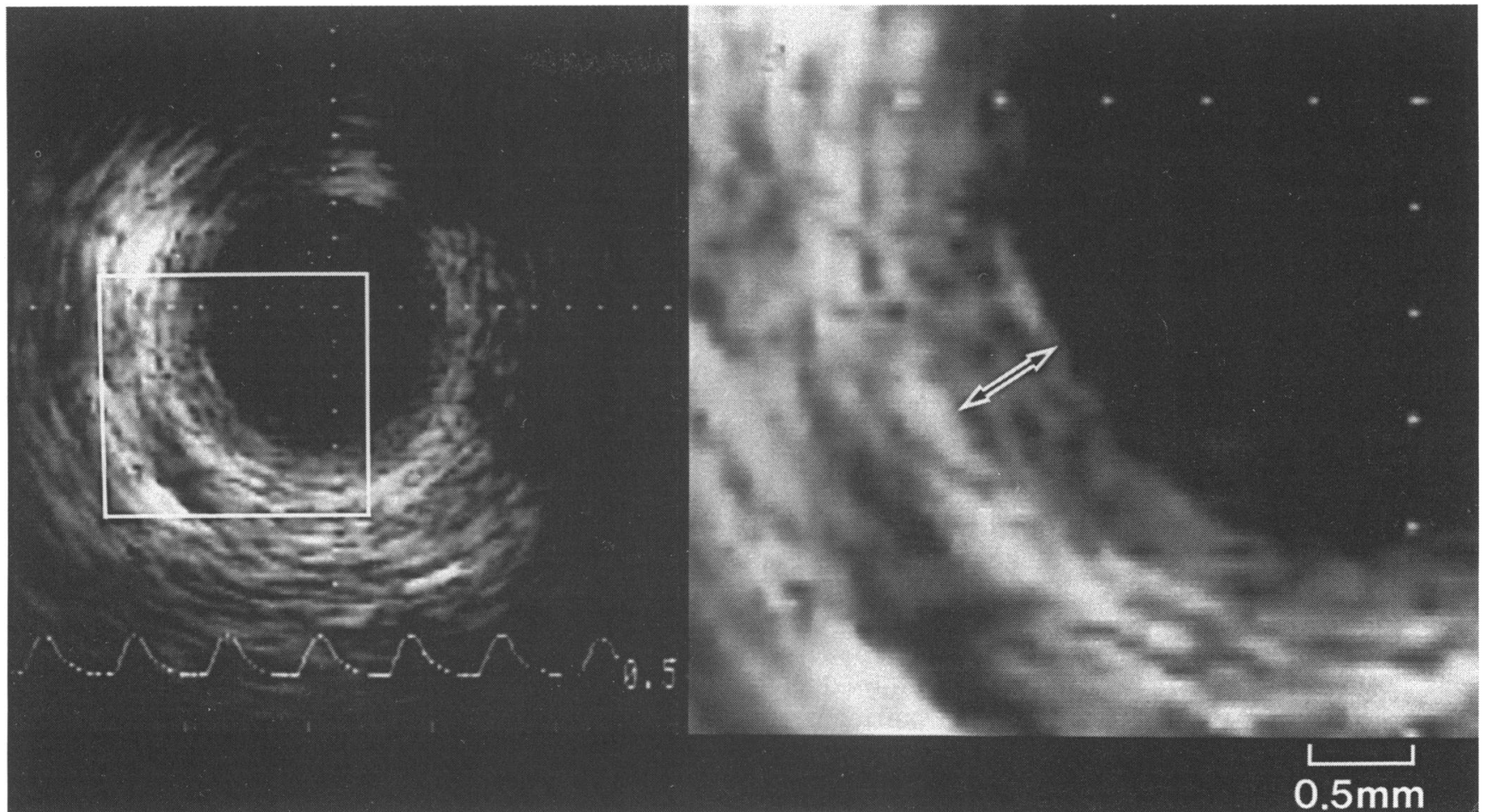

Figure 1 Intravascular ultrasound image (left panel) of saphenous vein graft 12 months after implantation, and magnified view of a portion of this image showing measurement of the intimal thickness (right panel). Intimal thickness was measured from the luminal border to the external border of hypoechoic layer.

and lateral resolution of about $200 \mu \mathrm{m}$ which are based on the empirical data. ${ }^{17}$ During each study, the gain, reject, and compression settings were adjusted to generate images with the largest grey scale range. Images were acquired at 30 frames per second and recorded on high-quality videotape (s-VHS, 0.5 inch) for off-line analysis. An $8 \mathrm{~F}$ soft-tip Judkins guiding catheter (Schneider, USA) was inserted into the orifice of the saphenous vein graft. The imaging catheter was inserted into the vein graft over a 0.014 inch flexible steerable angioplasty guidewire (USCI), and positioned in the orifice of the graft. Intravascular ultrasound images were obtained from three to five cross sections in the proximal portion of each graft. The proximal portion of the graft was 2 to $3 \mathrm{~cm}$ distal to the orifice of the graft. Three to five cross sections were taken at $2 \mathrm{~mm}$ intervals by a pullback system (CVIS). At the time of the first study, we confirmed the position of the catheter under biplane fluoroscopic monitoring with contrast injection, and we tried to set the imaging catheter at the same site at the follow up study.

\section{ULTRASOUND ANALYSIS}

Ultrasound images were digitised by an imageprocessing computer (NEC). Intimal thickness was measured from the luminal border to the external border of hypoechoic layer in each graft (fig 1). We measured intimal thickness every $90^{\circ}$ around the lumen circumference on the images and the mean of these four measurements was taken as the intimal thickness. The mean intimal thickness of each graft was obtained from the intimal thickness of three to five cross-sections in the proximal segment of the graft.
The luminal area was measured by tracing lumen-vessel wall interface by planimetry. The external border of hypoechoic layer was traced by planimetry, and total area was measured. The intimal area was defined as the difference between the total area minus the luminal area.

\section{DATA ANALYSIS}

We used Student's paired $t$ test to compare the mean intimal thickness of the grafts one month after implantation with those at 12 months. A probability value of less than 0.05 was regarded as statistically significant.

Fifteen ultrasound cross sections from five grafts were randomly selected and the intimal thickness was measured randomly and blindly by two observers. The interobserver variability was calculated as a percentage error. One observer measured intimal thickness on two separate occasions to determine intraobserver variability, which was calculated as a coefficient of repeatability.

\section{Results}

INTIMAL THICKNESS

The ultrasound image showed a thin-walled graft one month after operation (fig 2, left). The mean intimal thickness of the grafts was $0.31(0.09) \mathrm{mm}$ one month after operation (fig 3). At 12 months after operation, the ultrasound images showed a graft with a thickened wall (fig 2, right). Mean intimal thickness was significantly increased to $0.65(0.08) \mathrm{mm}(\mathrm{P}<$ 0.001 , fig 3) 12 months after operation. No calcified plaques or lipid deposits were seen in any cases.

INTIMAL AREA

The mean intimal area of the graft was 0.90 
Figure 2 Intravascular ultrasound images one month (left panel) and 12 months (right panel) after implantation at the same site in the saphenous vein graft of the same patient. The ultrasound image showed a thin-walled graft one month after

implantation. The intimal thickness of the graft was greater 12 months after implantation than one month after implantation.

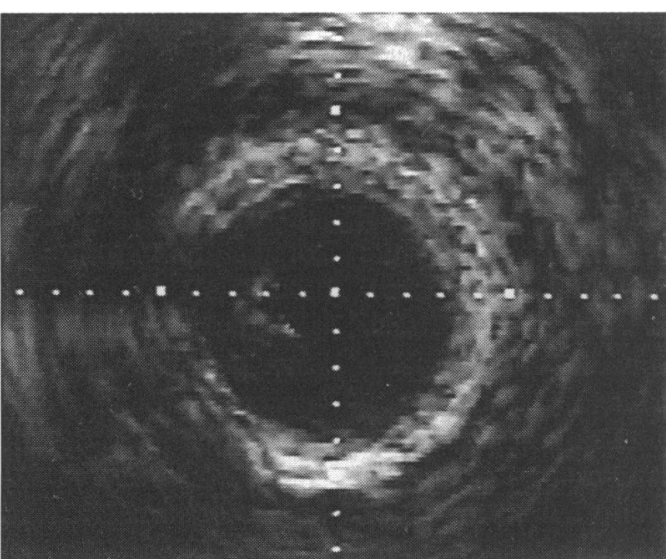

$P<0.001$

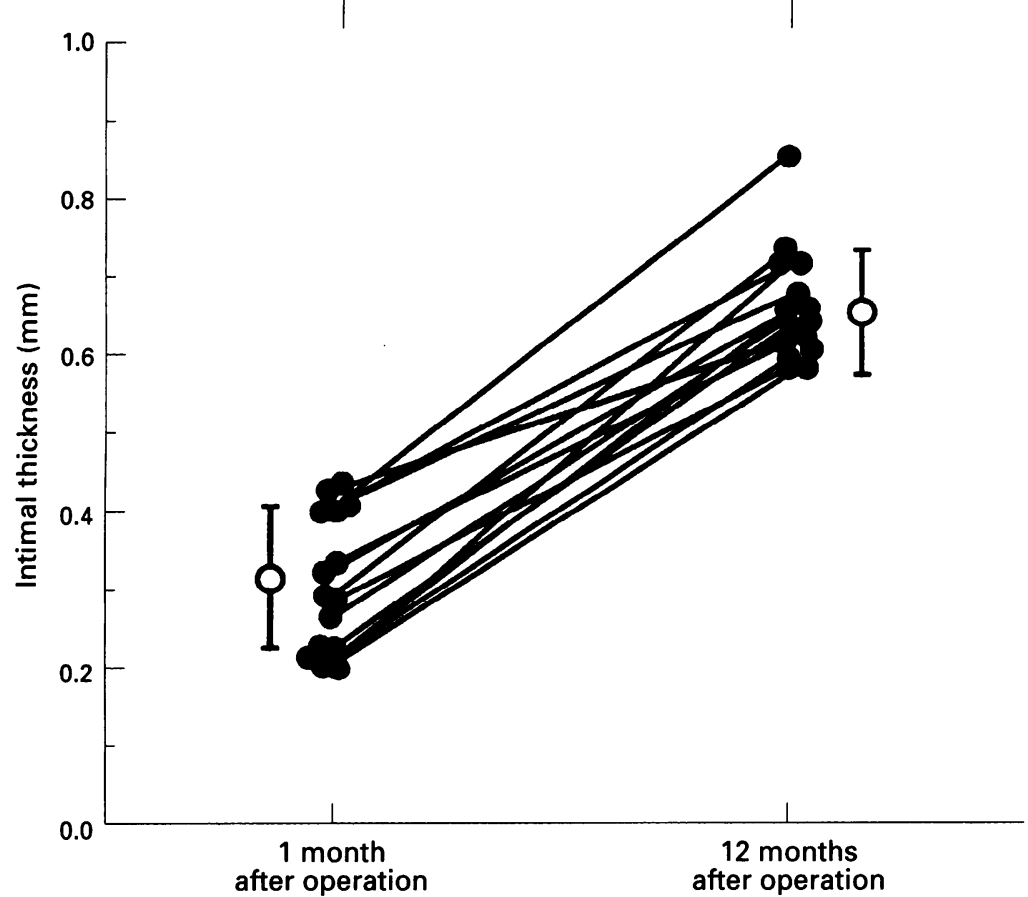

Figure 3 Intimal thickness of saphenous vein grafts. Intimal thickness was greater 12 months after operation than one month after operation.

$(0 \cdot 80) \mathrm{mm}^{2}$ one month after operation. At 12 months after operation, the intimal area had increased significantly to $5.26(1.38) \mathrm{mm}^{2}$ (P $<0.001$ ).

OBSERVER VARIABILITIES

The interobserver variability for intimal thickness was $4 \cdot 8 \%$. Agreement was uniformly close throughout the range of intimal thickness, with a correlation coefficient of 0.99 (y $=1.03 \mathrm{x}-0.02)$.

\section{Discussion}

We found that the intimal thickness and intimal area of the saphenous vein grafts were significantly increased 12 months after implantation compared with those measured one month after implantation.

Previous pathological studies have shown morphological changes in the vessel wall of saphenous vein grafts that developed as a consequence of veins being used as arterial conduits. ${ }^{1-7}$ In several studies, contrast angiographic examinations, which are currently the

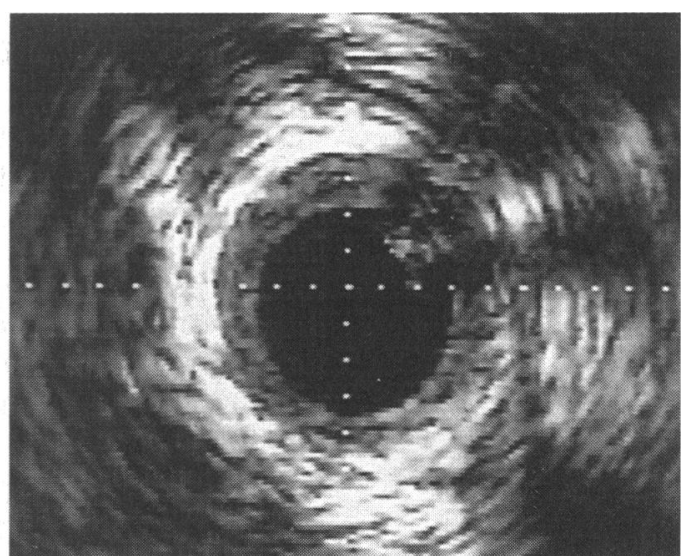

standard for in vivo quantitation and morphological evaluation of coronary atherosclerosis, $^{2122}$ were performed to evaluate the morphological changes in saphenous vein grafts. ${ }^{236}$ Though this technique can show wall irregularities and localised or diffuse severe narrowings, pathology-angiography correlation studies showed marked angiographic underestimation of atheromatous plaque because they were limited to a luminal silhouette. ${ }^{8-10}$ Thus angiography has limitations when it is used to evaluate the morphological characteristics of the vessel wall.

St Goar et al showed that intravascular ultrasound can detect and measure transplant coronary disease at an early stage and determine vessel wall morphology in angiographically normal coronary arteries. ${ }^{18}$ Another study showed that intravascular ultrasound provides morphological characterisation of the wall of saphenous vein grafts that accords with histological data in vitro. ${ }^{19} \mathrm{~A}$ clinical study by NaseHueppmeier et al showed that intravascular ultrasound investigation of saphenous vein grafts in vivo is feasible and safe. ${ }^{20}$ In their study, however, changes in graft wall morphology were not examined in the same patient. We, however, used intravascular ultrasound to compare the intimal thickness of saphenous vein grafts at follow up with that early after implantation in the same patient. To our knowledge, the present study is the first report to evaluate changes in the intimal thickness of saphenous vein grafts after implantation in vivo.

Intravascular ultrasound images showed that one month after implantation the saphenous vein grafts had a thin intima and that at 12 months after implantation this had increased significantly. Previous pathological studies have shown that intimal thickening appears in saphenous vein grafts more than one month after implantation as an adaptive change caused by their being connected to the arterial pressure system. ${ }^{124}$ One pathological study showed considerable intimal fibrotic proliferation in each saphenous vein graft used as an aortocoronary bypass conduit for 3.5 months or longer but no changes in grafts that had been in place for less than one month. ${ }^{1}$ Another pathological study found various degrees of intimal thickening in all aortocoronary saphenous vein grafts from patients who survived more than one month after opera- 
tion. ${ }^{2}$ Although the pathogenesis of intimal changes of saphenous vein graft remains unclear, ${ }^{1-5}$ earlier reports suggest that intimal thickening is a natural consequence of subjecting a vein to arterial pressure. ${ }^{1}$ In all grafts in our study, angiograms showed no irregularities or narrowings, and intravascular ultrasound showed no findings suggesting atherosclerosis such as calcium or lipid deposits. Willard et al using intravascular ultrasound showed a faint echolucent band within the vessel lumen of saphenous vein grafts that correlated with the intimal hyperplasia seen on histological examination. ${ }^{19}$ We measured the thickness from the luminal border to the external border of hypoechoic layer, which is thought to correspond to the intima. We believe that the increase that we measured in the thickness of the vein grafts in this study represents thickening of the intima as consequence of increased pressure.

We showed that the intimal thickness of saphenous vein grafts had increased 12 months after operation. We do not know whether this change would have progressed at later follow up. Although previous studies reported that intimal thickening does not progress in proportion to the time since operation, a further follow up study using intravascular ultrasound is needed to clarify this point.

\section{CONCLUSION}

Intravascular ultrasound showed that the thickness of the intima of angiographically normal saphenous vein grafts 12 months after implantation was greater than it was one month after implantation, probably as a result of subjecting a vein to arterial pressure.

We thank Mr Junichi Yamashita, Mr Fumio Inoue, and $\mathrm{Mr}$ Hiroshi Kubo, the radiological technicians, for their assistance in recording the intravascular ultrasound images.

1 Vlodaver Z, Edwards JE. Pathologic changes in aortic-coronary arterial saphenous vein grafts. Circulation 1971;47: 719-28.

2 Unni KK, Kottke BA, Titus JL, Frye RL, Wallace RB, Brown AL. Pathologic changes in aortocoronary saphenous vein grafts. Am $₹$ Cardiol 1974;34:526-32.

3 Lawrie GM, Lie JT, Morris GC, Beasley HL. Vein graft patency and intimal proliferation after aortocoronary bypass: early and long-term angiopathologic correlations. bypass: early and long-term ang
Am Cardiol 1976;38:856-62.

4 Spray TL, Roberts WC. Changes in saphenous veins used as aortocoronary bypass grafts. Am Heart $\mathcal{f}$ 1977;94: 500-16.
5 Lie JT, Lawrie GM, Morris GC. Aortocoronary bypass saphenous vein graft atherosclerosis: anatomic study of 99 vein grafts from normal and hyperlipoproteinemic patients up to 75 months postoperatively. Am 7 Cardio 1977;40:906-14.

6 Campeasu L, Enjalbert M, Lesperance J, Vaislic C, Grondin CM, Bourassa MG. Atherosclerosis and late closure of aortocoronary saphenous vein grafts: sequential angiographic studies at 2 weeks, 1 year, 5 to 7 years, and 10 to 12 years after surgery. Circulation 1983;68 and 10 to 12 years

7 Smith SH, Geer JC. Morphology of saphenous vein-coronary artery bypass grafts. Arch Pathol Lab Med 1988;107 13-8.

8 Achwartz JN, Kong Y, Hackel DB, Bartel AG. Comparison of angiographic and postmortem findings in patients with coronary artery disease. Am $\mathcal{F}$ Cardiol $1975 ; 36: 174-8$.

9 Arnett RN, Isner JM, Redwood D. Coronary artery narrowing in coronary heart disease: comparison of cineangiographic and necropsy findings. Ann Intern Med 1979 36:174-8.

10 Marcus ML, Skortoy DJ, Johnson MR, Collins SM, Harrison DG, Kerber RE. Visual estimates of percent diameter coronary stenosis: "a battered gold standard." $\mathcal{F}$ Am Coll Cardiol 1988;11:882-5.

11 Gussenhoven EJ, Essed CE, Lancee CT, Mastik F, Frietman P, Van Egmond FC, et al. Arterial wall characFrietman $\mathrm{P}$, Van Egmond FC, et al. Arterial wall characteristics determined by intravascular ultrasound imagin

12 Nishimura RA, Edwards WD, Warnes CA, Reeder GS Nishimura RA, Edwards WD, Warnes CA, Reeder GS,
Holmes DR Jr, Tajik AJ, et al. Intravascular ultrasound imaging: in vitro validation and pathologic correlation. $f$ Am Coll Cardiol 1990;16:145-54

13 Nissen SE, Grines CL, Gurley JC, Sublett K, Haynie D, et al. Application of a new phased-array ultrasound imagin catheter in the assessment of vascular dimensions: in vivo comparison to cineangiography. Circulation 1990;81 $660-6$

14 Tobis JM, Mallery J, Mahon D, Lehmann K, Zalesky P, Griffith $\mathrm{J}$, et al. Intravascular ultrasound imaging of human coronary arteries in vivo: analysis of tissue charachuman coronary arteries in vivo: analysis of tissue characterizations with comparison to in

15 St Goar FG, Pinto FJ, Alderman EL, Fitzgerald PJ, Stadius ML, Popp RL. Intravascular ultrasound imaging of angiographically normal coronary arteries: an in vivo comparison with quantitative angiography. $\mathcal{f} \mathrm{Am} \mathrm{Coll}$ Cardiol 1991;18:952-8.

16 Pinto FJ, Goar FG, Fischell TA, Stadius ML, Valantine HA, Alderman EL, et al. Nitroglycerin-induced coronary vasodilation in cardiac transplant recipients: evaluation with in vivo intracoronary ultrasound. Circulation 1992 85:69-77

17 Fitzgerald PJ, Goar FG, Connolly AJ, Pinto FJ, Billingham ME, Popp RL, et al. Intravascular ultrasound imaging of coronary arteries: is three layers the norm? Circulation 1992;86:154-8

18 St Goar FG, Pinto FI, Alderman EL, Valantine HA, Schroeder JS, Gao SZ, et al. Intracoronary ultrasound in cardiac transplant recipients: in vivo evidence of "angiocardiac transplant recipients: in vivo evidence of "angio85:979-87

19 Willard JE, Netto D, Demian SE, Haagen DR, Brickner E, Eichhorn EJ, et al. Intravascular ultrasound imaging of saphenous vein grafts in vitro: comparison with histologic and quantitative angiographic findings. $\mathcal{f} \mathrm{Am}$ Coll Cardiol 1992;19:759-64.

20 Nase-Hueppmeier S, Uebis R, Doerr R, Hanrath P. Intravascular ultrasound to assess aortocoronary venous bypass grafts in vivo. Am $\mathcal{F}$ Cardiol 1992;70:455-458.

21 Brown BG, Bolson EL, Dodge HT. Quantitative computer techniques for analyzing coronary arteriograms. Prog Cardiovasc Dis 1986;28:403-18.

22 Reiber JHC, Serruys PW, Kooijman JC, Wijns W, Slager CJ, Gerbrands JJ, et al. Assessment of short-, medium-, and long-term variations in arterial dimensions from computer-assisted quantitation of coronary cineangiograms. Circulation 1985:71:280-8 